\title{
Altha J. Stewart, MD, on the state of psychiatry
}

\author{
Awais Aftab, MD, and Altha J. Stewart, MD
}

$\mathrm{F}$ or this Psychiatry Leaders' Perspectives, Awais Aftab, MD, interviewed Altha J. Stewart, MD. Dr. Stewart is Senior Associate Dean for Community Health Engagement at the University of Tennessee Health Science Center (UTHSC)-Memphis. She also serves as Chief of the Division of Social and Community Psychiatry and Director, Center for Health in Justice Involved Youth at UTHSC, where she manages community-based programs serving children impacted by trauma and mental illness and their families. In 2018, she was elected President of the American Psychiatric Association, the first African American individual elected in the 175-year history of the organization.

Dr. Aftab: Structural racism in academic and organized psychiatry is an issue that is close to your heart. What is your perspective on the current state of structural racism in American psychiatry, and what do you think we can do about it?

Dr. Stewart: That's a good question to start with because I think the conversations that we need to have in academia in general and in academic psychiatry specifically really do frame the current issues that we are facing, whether we're talking about eliminating health disparities or achieving mental health equity. Historically, from the very beginning these discussions have been structured in a racist manner. The early days of American psychiatry were very clearly directed towards maintaining a system that excluded large segments of the population of the time, since a particularly violent form of chattel slavery was being practiced in this country.

The mental health care system was primarily designed for the landowning white men of some standing in society, and so there was never any intent to do much in the way of providing quality humane service to people who were not part of that group. What we have today is a system that was designed for a racist societal structure, that was intended to perpetuate certain behaviors, policies, and practices that had at their core a racist framework. We have to acknowledge and start from this beginning point. This is not to blame anyone currently alive. These are larger structural problems. Before we can begin setting up strategic plans and other actions, we have to go back and acknowledge how we got here. We have to accept the responsibility for being here, and then we have to allow the conversations that need to happen to happen in a safe way, without further alienating people, or maligning and demeaning people who are for the most part well-intentioned but perhaps operating on automatic pilot in a system that is structurally racist.

Dr. Aftab: Do you think that the conversations that need to happen are taking place?

continued

Dr. Aftab is Clinical Assistant Professor, Psychiatry, Case Western Reserve University, Cleveland, Ohio. Dr. Stewart is Senior Associate Dean for Community Health Engagement, University of Tennessee Health Science Center-Memphis.

Disclosures

The authors report no financial relationships with any companies whose products are mentioned in this article, or with manufacturers of competing products.

doi: $10.12788 /$ cp.0133

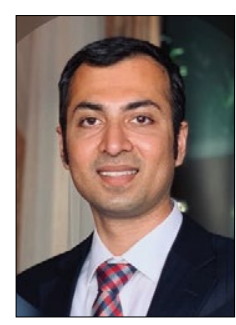

Awais Aftab, MD

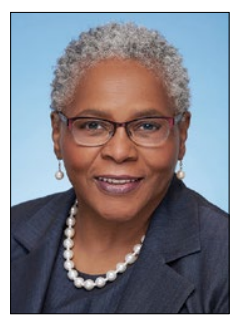

Altha J. Stewart, MD

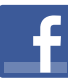

Discuss this article at www.facebook.com/ MDedgePsychiatry 


\section{Clinical Point}

I have been
encouraged that
what we do ... really
does improve the
quality of life for the
people we serve

Dr. Stewart: Yes, I think they are beginning to happen. I do a fair number of talks and grand rounds, and what I discover when I meet with different academic departments and different groups is that most places now have a diversity committee, or the residents and students have assigned themselves as diversity leaders. They are really pushing to have these conversations, to insert these conversations into the training and education curricula. The structures in power are so deeply entrenched that many people, particularly younger people, are easily frustrated by the lack of forward motion. One of the things that seasoned leaders in psychiatry have to do is to help everyone understand that the movement forward might be glacial in the beginning, but any movement forward is good when it comes to this. The psychiatrists of my generation talked about cultural competence in psychiatry, but generations of today talk about structural competence. These are similar concepts, except that cultural competency worked within the traditional model, while structural competency recognizes that the system itself needs to change. I find this development very encouraging.

Dr. Aftab: What do you see as some of the strengths of our profession?

Dr. Stewart: I am a hopeful optimist when it comes to psychiatry. I have dedicated my professional life to psychiatry and specifically to community psychiatry. Throughout the time that I have practiced psychiatry, I have been encouraged that what we do as a medical specialty really does improve the quality of life for the people we serve. Situationally right now, we're in a unique position because the COVID pandemic has laid open and then laid bare the whole issue of how we deal with psychological distress, whether it's diagnosed mental illness or a natural, normal response to a catastrophic event. We are the experts in this. This is our sweet spot, our wheelhouse, whatever analogy you prefer. This is the moment where we assert our expertise as the leaders-not as service add-ons, not as followers, not as adjuncts, but as the leaders.

I am so impressed with the next generation of psychiatrists. They have a wonderful blend of pride and privilege at what they have been able to accomplish to get to the point where they are doctors and psychiatrists, but they have aligned that with a strong core sense of social justice, and they are moved by their responsibility to the people in the society around them.

Another strength of our profession is what we consider to be the "art" of psychiatry. That is, the way we marry the relational aspects of psychiatry with the biological, technical, and digital aspects to arrive at a happy collaboration that benefits people. It is our great skill to engage people, to interact with them therapeutically, to recognize and acknowledge the nonverbal cues. This skill will be even more important in the age of online mental health services. I'm an "old-school" therapist. I like that faceto-face interaction. I think it's important to preserve that aspect of our practice, even as we move towards online services.

Dr. Aftab: Are there ways in which the status quo in psychiatry falls short of the ideal? What are our areas of relative weakness?

Dr. Stewart: I don't think we can afford to remain in status quo, because we need to constantly think and rethink, evaluate and re-evaluate, assess things in the light of new information. Particularly if we're talking about people who rely on public funding to get even the bare minimum services, status quo doesn't cut it. It's not good enough. I had a teacher during my residency, a child psychiatrist, who used to say, "Good, better, best. Never let it rest, until your good is better and your better is best." Something about that has stuck with me. As my career progressed, I heard variations of it, including one from former 
Surgeon General of the United States David Satcher, who was not a psychiatrist, but pulled together the group that published the first Surgeon General's report on mental health, followed by the Surgeon General's report on mental health, culture, race, and ethnicity. He had the penetrating insight that risk factors are not to be accepted as predictive factors due to protective factors. If I am at risk for mental illness or a chronic medical condition based on my race or ethnicity or socioeconomic status or employment status, this does not mean that I am destined to experience that illness. In fact, we are not doing our job if we accept these outcomes as inevitable and make no attempt to change them. So, for me, if we accept the status quo, we give up on the message of "Good, better, best. Never let it rest, until your good is better and your better is best."

Dr. Aftab: What is your perception of the threats that psychiatry faces or is likely to face in the future?

Dr. Stewart: Well, this is going to sound harsh, and I do hope that the readers do not feel that I intend it to be harsh. We get in our own way. I work in the public sector, for example, and the reality is that there aren't enough psychiatrists to provide all the necessary psychiatric services for the people who need them. So many mental health clinics and practices employ other mental health professionals, whether they are psychologists or nurse practitioners or physician assistants with special training in mental health to provide those services. To have a blanket concern about anyone who is not an MD practicing in what is considered "our area" just begs the question that if we can't do it and we don't have enough psychiatrists to do it, should people just not get mental health treatment? Is that the solution? I don't think so. I don't think that's what people want, either, but because of the energy that gets aroused around these issues, we lose sight of that end goal. I think the answer is that we must take leadership for ensuring that our colleagues are welltrained, maybe not as well-trained as physicians, but well-trained enough to provide good care working under our supervision.

Dr. Aftab: What do you envision for the future of psychiatry? What sort of opportunities lie ahead for us?

Dr. Stewart: I think we are moving naturally into the space of integrated or collaborative care. I think we're going to have to acknowledge that going forward, the path to being a good psychiatrist means that we will also be consultants. Not just the consultation-liaison kind of consultant that we typically think of, but a consultant to the rest of medicine around shaping programs, addressing how we treat comorbid illness, looking at ways to minimize the morbidity and mortality associated with some of the chronic medical and mental diseases. We're moving naturally in that direction. For some people, that must be frightening. All throughout medicine people are witnessing change, and we need to adapt. I would hope that the specialty that is designed to help others deal with change will figure out how to use those skills to help themselves deal with the changes that are coming!

\section{Clinical Point}

I think we are moving naturally into the space of integrated or collaborative care ... and we need to adapt 